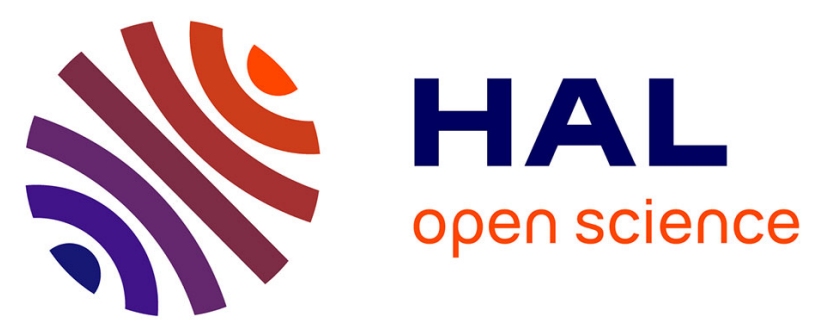

\title{
In vitro assessment of cobalt oxide particle dissolution in simulated lung fluids for identification of new decorporating agents
}

\author{
Anne van Der Meeren, David Lemaire, Sylvie Coudert, Guillaume Drouet, \\ Myriam Benameur, Célia Gouzerh, Cien Yoong Hee, Pauline Brunquet, \\ Bastien Trochaud, Magali Floriani, et al.
}

\section{To cite this version:}

Anne van Der Meeren, David Lemaire, Sylvie Coudert, Guillaume Drouet, Myriam Benameur, et al.. In vitro assessment of cobalt oxide particle dissolution in simulated lung fluids for identification of new decorporating agents. Toxicology in Vitro, 2020, 66, pp.104863. 10.1016/j.tiv.2020.104863 . hal-02922342

\section{HAL Id: hal-02922342 \\ https://hal.science/hal-02922342}

Submitted on 27 Aug 2020

HAL is a multi-disciplinary open access archive for the deposit and dissemination of scientific research documents, whether they are published or not. The documents may come from teaching and research institutions in France or abroad, or from public or private research centers.
L'archive ouverte pluridisciplinaire HAL, est destinée au dépôt et à la diffusion de documents scientifiques de niveau recherche, publiés ou non, émanant des établissements d'enseignement et de recherche français ou étrangers, des laboratoires publics ou privés. 
 \\ IN VITRO ASSESSMENT OF COBALT OXIDE PARTICLE DISSOLUTION}

2

\section{IN SIMULATED LUNG FLUIDS FOR IDENTIFICATION OF NEW}

\section{DECORPORATING AGENTS}

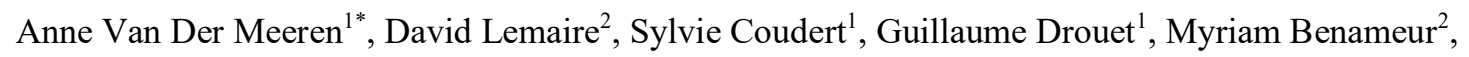
Célia Gouzerh ${ }^{1}$, Cien Yoong Hee ${ }^{4}$, Pauline Brunquet ${ }^{4}$, Bastien Trochaud ${ }^{2}$, Magali Floriani ${ }^{3}$, Christelle

Gateau $^{4}$, Colette Lebrun ${ }^{4}$, Pascale Delangle ${ }^{4}$, Catherine Berthomieu ${ }^{2}$ and Véronique Malard ${ }^{2 *}$

': Laboratory of Radio Toxicology, CEA, Paris-Saclay University, 91297 Arpajon, France

2: Aix Marseille Univ, CEA, CNRS, BIAM, UMR7265, IPM, 13108 Saint Paul-Lez-Durance, France

3: Institut de Radioprotection et de Sûreté Nucléaire (IRSN), PSE-ENV/SRTE/LECO, Cadarache,

13115, Saint-Paul-lez-Durance, France

4: Univ. Grenoble Alpes, CEA, CNRS, IRIG, SyMMES, F-38000 Grenoble, France

*Corresponding authors : Anne Van Der Meeren, Véronique Malard

*e-mail: anne.vandermeeren@cea.fr - veronique.malard@cea.fr; ORCID ID: 0000-0002-0020-0518

Véronique Malard, DRF/BIAM bat 185, UMR 7265 CNRS CEA Aix-Marseille Univ. CEA-Cadarache 13108 Saint Paul-lez-Durance. TEL : +33 442254277 - FAX : +33 442252625

The authors declare that they have no conflict of interest.

\section{Acknowledgements}

The authors would like to acknowledge Carole Bresson (CEA/DEN), Nina Griffiths (CEA/DRF), Laurence Lebaron-Jacobs (CEA/DRF) and Simon Duval (CNRS/AMU) for fruitful discussions. This work was supported by the company Electricité De France (EDF). 


\section{Abstract}

27 Inhalation of ${ }^{60} \mathrm{Co}_{3} \mathrm{O}_{4}$ particles may occur at the work place in nuclear industry. Their low solubility may

28 result in chronic lung exposure to $\gamma$ rays. Our strategy for an improved therapeutic approach is to enhance

29 particle dissolution to facilitate cobalt excretion, as the dissolved fraction is rapidly eliminated, mainly

30 in urine.

31 In vitro dissolution of $\mathrm{Co}_{3} \mathrm{O}_{4}$ particles was assessed with two complementary assays in lung fluid

32 surrogates to mimic a pulmonary contamination scenario. Twenty-one molecules and eleven

33 combinations were selected through an extensive search in the literature, based on dissolution studies of

34 other metal oxides ( $\mathrm{Fe}, \mathrm{Mn}, \mathrm{Cu})$ and tested for dissolution enhancement of cobalt particles after 1 to 28

35 days of incubation.

36 DTPA, the recommended treatment following cobalt contamination did not enhance ${ }^{60} \mathrm{Co}_{3} \mathrm{O}_{4}$ particles

37 dissolution when used alone. However, by combining molecules with different properties, such as redox

38 potential and chelating ability, we greatly improved the efficacy of each drug used alone, leading for the

39 highest efficacy, to a 2.7 fold increased dissolution as compared to controls. These results suggest that

40 destabilization of the particle surface is an important initiating event for a good efficacy of chelating

41 drugs, and open new perspectives for the identification of new therapeutic strategies.

43 Keywords: cobalt oxide particles, bioaccessibility, dissolution and chelating agents, lung, in vitro. 


\section{Introduction}

Cobalt (Co) is widely used in industrial processes for its magnetic properties, corrosion resistance, wear resistance, and/or its strength at elevated temperatures (Barceloux, 1999). The $\gamma$-emitter ${ }^{60} \mathrm{Co}$ is a neutron activation product formed from structural materials in nuclear reactors. During procedures such as maintenance, ${ }^{60} \mathrm{Co}$ can be released as highly mobile and highly radiant oxide particles. Accidental internal or cutaneous contamination of workers may thus arise (Davis et al., 2007; Le Guen and Ansoborlo, 2005). In addition to the risk of exposure for workers in the nuclear industry, ${ }^{60} \mathrm{Co}$ has been identified as a potential candidate for use in a "dirty bomb" (Rump et al., 2018). Such a device could lead to the contamination of a great number of victims by fallout of radioactive dusts.

Cobalt oxide particles $\mathrm{Co}_{3} \mathrm{O}_{4}$ are poorly soluble compounds, classified as $\mathrm{S}$ (slow) by the International Commission on Radiological Protection (ICRP) based on the transfer rate from lungs to blood following pulmonary contamination (ICRP, 2016). Following inhalation of ${ }^{57} \mathrm{Co}_{3} \mathrm{O}_{4}$ particles in baboons, only 40 $\%$ of initially deposited particles were cleared 6 months post-exposure (Kreyling et al., 1991). Shortterm clearance resulted from particle transfer to the larynx, whereas, longer-term clearance was due to the translocation of dissociated Co to the blood. Once this dissolved Co fraction reaches the blood compartment, it is rapidly eliminated, with a Co half-life of 12 hours. More precisely, a recent study in rats has shown that $67.6 \%$ of cobalt administered as the soluble form, ${ }^{60} \mathrm{CoCl}_{2}$, is excreted in urine with a half-life of $1.9 \mathrm{~h}$, and $34.5 \%$ with a half-life of $45 \mathrm{~h}$ (Weber et al., 2012). The chemical toxicity of Co has been found higher for soluble compounds than for $\mathrm{Co}_{3} \mathrm{O}_{4}$ particles (Ortega et al., 2014). However, following inhalation of insoluble radioactive cobalt particles, long-term consequences such as lung fibrosis or lung cancer could occur as a result of its radiological toxicity.

Whatever the route of internal contamination by ${ }^{60} \mathrm{Co}_{3} \mathrm{O}_{4}$ particles $\left({ }^{60} \mathrm{Co}_{3} \mathrm{O}_{4} \mathrm{P}\right)$, the current recommendation for the management of contamination is the intravenous administration of Ca-DTPA

(Diethylenetriamine-pentaacetic acid calcium trisodium salt hydrate) or EDTA (Ethylenediaminetetraacetic acid disodium salt dihydrate), although inhalation of DTPA can also be considered following lung contamination (ASN, 2008; REMM). Animal studies aiming at determining the efficacy of various drugs, including DTPA, have been carried out essentially following systemic 
contamination with soluble forms of cobalt (Fisher and Dunavant, 1978; Levitskaia et al., 2010a; Levitskaia et al., 2011; Levitskaia et al., 2010b; Llobet et al., 1986, 1988; Zylicz et al., 1975). Treatments with both DTPA and EDTA increased cobalt excretion and decreased cobalt retention in several tissues (Fisher and Dunavant, 1978; Llobet et al., 1986, 1988; Zylicz et al., 1975). Some success has also been obtained with molecules selected for their $\mathrm{Co}^{2+}$-binding properties, such as $\mathrm{N}$-acetyl-1-cysteine, $\mathrm{D}$ or $\mathrm{L}$ penicillamine, L-cysteine, trientine or glutathione (Levitskaia et al., 2010a; Levitskaia et al., 2011; Levitskaia et al., 2010b; Llobet et al., 1986, 1988). Some of these molecules, namely D-penicillamine and trientine, are also efficient treatments for copper detoxification in Wilson Disease (Delangle and Mintz, 2012). Human cases of cobalt toxicity have been reported following high serum concentrations of $\mathrm{Co}^{2+}$ resulting from leaching of Co-containing prostheses. Administration of $\mathrm{N}$-acetyl-cysteine significantly decreased $\mathrm{Co}^{2+}$ concentration in blood (Giampreti et al., 2016) whereas EDTA had only at transient efficacy (Pazzaglia et al., 2011). Following inhalation of ${ }^{60} \mathrm{Co}_{3} \mathrm{O}_{4} \mathrm{P}$, the most likely scenario at the work place, chelation by DTPA is expected to concern mainly the ionized form of cobalt, $\mathrm{Co}^{2+}$, suggesting that DTPA treatment would have limited efficacy. Indeed, in case of inhalation of poorly soluble compounds, such as plutonium oxides, only the solubilized fraction present in lung fluids was accessible to DTPA (Gremy et al., 2010). To our knowledge, neither DTPA nor the other potential decorporating agent efficacy have ever been tested after exposure to cobalt oxides.

Decorporation aims at increasing excretion and reducing the retention of the contaminant. The main retention site following inhalation of cobalt particles is the lungs. Pulmonary clearance reflects a multistage process, integrating the dissolution of the contaminant, the interactions with (biological) ligands and the absorption into fluids. Inhaled particles are rapidly engulfed by macrophages, where they may remain trapped for long periods. The determining process in the transfer of Co from lungs to blood has been shown to be the intracellular dissolution of the Co particles in the macrophages (Kreyling et al., 1993). The $\mathrm{Co}^{2+}$ ionic species generated by the dissolution process become bioavailable to chelating drugs. Therefore, enhancing dissolution may represent the first step in the clearance of poorly soluble particles, by increasing the fraction of the contaminant available to chelating drugs. To fulfill the recommendations of the European directive 2010/63/EU, the principles of the "3Rs" (Replacement, Reduction and Refinement) must be considered systematically at all times when animals are used for 
scientific purposes. These principles were first proposed by Russell and Burch (Russell and Burch, 1959). They are currently proposed as the key strategies of a systematic framework aimed at achieving human use of any drugs. A recent paper demonstrates the applicability of the 3 Rs in the field of radiotoxicology (Griffiths et al., in press), and particularly the use of adequate dissolution assays to provide information on solubility and bioaccessibility of various contaminants.

Whereas extensive literature on the dissolution of other oxide particles exists, only a few studies have been dedicated to the dissolution of $\mathrm{Co}_{3} \mathrm{O}_{4} \mathrm{P}$ (Cho et al., 2012; Collier et al., 1992; Lundborg et al., 1992; Ortega et al., 2014). Since the most likely scenario for accidental exposure at the work place is the inhalation of cobalt particles, our approach consisted in the evaluation of various categories of molecules for their efficacy in $\mathrm{Co}_{3} \mathrm{O}_{4} \mathrm{P}$ dissolution. We successively tested: 1- molecules for which an efficacy to decorporate soluble $\mathrm{Co}^{2+}$ has been previously described, 2- various known $\mathrm{Co}^{2+}$-binding molecules and 3- metal-binding sulfur-containing pseudopeptides. We then broadened our tests to molecules known for their ability to increase the dissolution of various metal oxides and to associations of molecules with complementary properties.

To foresee the use of these molecules in in vivo experiments and ultimately in man, FDA approved or non-toxic molecules were preferentially selected. The dissolution of a contaminant will depend on the intrinsic physicochemical properties of this contaminant as well as physicochemical and physiological properties of the biological environment, such as extra- and intra-cellular chemical constituents (Hedberg et al., 2010; Kastury et al., 2017; Pelfrene et al., 2017; Staack et al., 2017; Stefaniak, 2010). Thus, a large number of molecules was tested in media mimicking lung fluids, Gamble's and ALF (Artificial Lysosomal Fluid), using a simple dissolution model in solution. Then, the molecules selected for their efficacy on $\mathrm{Co}_{3} \mathrm{O}_{4} \mathrm{P}$ dissolution were tested using a biphasic dynamic assay recently developed to assess the bioavailability of actinides (Van der Meeren et al., 2019). This assay was used to better mimic the transfer of bioavailable species from a retention compartment (agarose gel) to a dynamic phase (transfer compartment), where the drugs were added. Relevant physiological conditions were obtained by introducing various components both in the static and dynamic phases. In addition, the data obtained from this assay with actinides was found to show good correlation between dissolution data and urinary excretion following contamination in rat (Griffiths et al., 2016). In this work, this assay was 
used as a first assessment to predict the fraction of $\mathrm{Co}_{3} \mathrm{O}_{4} \mathrm{P}$ that could potentially be transferred from retention compartments to the blood, as well as the $\mathrm{Co}^{2+}$ - fraction available to chelating drugs. $\mathrm{Co}_{3} \mathrm{O}_{4} \mathrm{P}$ with sizes representative of those produced in nuclear reactors were chosen (Davis et al., 2007; Ortega et al., 2014). Finally, since a similar chemical behavior can be expected in vitro whatever the isotope, the present studies were conducted with the stable isotope, ${ }^{59} \mathrm{Co}$.

Altogether, the use of in vitro assays allowed the testing of a great number of molecules thus opening new perspectives for novel therapeutic approaches. This study could represent a benchmark for the development of similar approaches, to test the dissolution of other relevant metal oxide particles.

\section{Materials and Methods}

\section{Reagents}

Nitric acid and hydrochloric acid of high purity grade $\left(\mathrm{HNO}_{3} 65 \%\right.$ Suprapur and $\mathrm{HCl} 35 \%$ Suprapur) were purchased from VWR. $\mathrm{Co}^{2+}$ solution for the ICP-MS calibration curves were prepared from standard solutions (1 mg. $\mathrm{L}^{-1}$ ), which were purchased from SPEX (SPEX Certiprep Company).

Diethylenetriamine-pentaacetic acid (DTPA Ca), 1-Hydroxyethylidenediphosphonic acid (HEDP), diphenylethylene diamine (DPEN), triethylene tetramine (TRIEN), N-Acetyl-L-cysteine (NAC), Lcysteine, Ethylenediaminetetraacetic acid (EDTA), L-Glutathione (GSH), DL-Dithiothreitol (DTT), Lascorbic acid, pyrocatechol, L-histidine, Imidazole, o-Phenylenediamine (OPD), 2,6Pyridinedicarboxylic acid (DIPIC), Oxalate, Deferoxamine mesylate salt (DFOB), Deferiprone (DFP), Ferrichrome, L-ornithine, Thiamine hydrochloride, Enterobactin, Tannic acid and Desferrithiocine (DFT) were purchased from Sigma-Aldrich. Ca-DTPA from PCA (Pharmacie Centrale des Armées, France) was used for the dynamic biphasic assay.

To enhance the relevance of the study, whenever possible and for already clinically used molecules, the concentration of molecules were chosen according to the recommendations for human use. As an example the recommended for intravenous daily administration of DTPA is $15-30 \mu$ mole $/ \mathrm{kg}$ depending of the body mass, which corresponds to roughly $500 \mu \mathrm{M}$ in blood at the time of administration. 
Cobalt particles $\left(\mathrm{Co}_{3} \mathrm{O}_{4} \mathrm{P}\right)$ were obtained from Sigma-Aldrich. The particle size $(370 \mathrm{~nm}$ diameter $)$ was chosen to be representative of particles involved in an incident at the work place for which a mean diameter was estimated to be of $410 \mathrm{~nm}$ (Davis et al., 2007).

$\mathrm{Co}_{3} \mathrm{O}_{4} \mathrm{P}$ were suspended in deionized water to prepare stock solutions with a cobalt concentration of 8 $\mathrm{mg} \mathrm{mL}^{-1}$; suspensions were then sonicated for $15 \mathrm{~min}$ with an Autotune sonicator (Fisher Scientific; Illkirch, France) operated at $750 \mathrm{~W}$, and stored at $-20{ }^{\circ} \mathrm{C}$ until use as previously described (Ortega et al., 2014; Uboldi et al., 2016).

$\mathrm{Co}_{3} \mathrm{O}_{4} \mathrm{P}$ characterization after 28 days of incubation was performed using Transmission Electron Microscopy (TEM) analysis. Eight $\mu 1$ of particle suspension in ascorbate and DFOB were deposited on carbon film - 200 mesh copper grids, and examined in a Tecnai $12 \mathrm{G}^{2}$ Biotwin scanning transmission electron microscope (Thermo Fisher Scientific, FEI Company, Eindhoven, the Netherlands) using an accelerating voltage of $100 \mathrm{kV}$ and coupled with a Megaview III (Olympus Soft imaging Solutions GmbH, Münster, Germany). Particle size was analyzed using the Image $\mathrm{J}$ software (https://imagej.nih.gov/, v.1.52n).

\section{Metal-binding sulfur pseudopeptides} Three metal-binding sulphur pseudopeptides were tested in the study. Their structure is based on polyaminocarboxylate scaffolds (NTA, EDTA or DOTA) grafted by 3 (for NTA) or 4 (for EDTA and DOTA) cysteine amide $\left(\mathrm{Cys}-\mathrm{NH}_{2}\right)$ residues (See Scheme $\mathrm{S} 1$ ). The synthesis of $\mathrm{NTA}\left(\mathrm{CysNH}_{2}\right)_{3}$ is reported in the literature (Pujol et al., 2011) and the two other derivatives, specifically designed for the study, $\mathrm{EDTA}\left(\mathrm{CysNH}_{2}\right)_{4}$ and DOTA $\left(\mathrm{CysNH}_{2}\right)_{4}$ were obtained using similar synthetic procedures. Material). 
All the solutions were prepared with deionized ultrapure water. Four media were used: $140 \mathrm{mM} \mathrm{NaCl}$, $5 \mathrm{mM} \mathrm{KCl}$ (pH 5.6), HEPES $20 \mathrm{mM}, \mathrm{NaCl} 100 \mathrm{mM}$ (pH 7.4), Gamble's solution (pH 7.4) and Artificial Lysosomal Fluid (ALF, pH 4.5). Gamble's and ALF were prepared according to Marques et al. (Marques et al., 2011). Buffers were filtered through a $0.22 \mu \mathrm{m}$ cellulose membrane filter and degassed half an hour before use.

\section{Dissolution assay in solution}

$1.2 \mathrm{~mL}$ of $\mathrm{Co}_{3} \mathrm{O}_{4} \mathrm{P}$ suspensions $(1 \mathrm{mM} \mathrm{Co})$ were prepared in medium containing various ligands at 500 $\mu \mathrm{M}$ concentration leading to ligand/cobalt ratios of 0.5 , unless mentioned, and incubated at $37^{\circ} \mathrm{C}$ under stirring (37 rpm) for 1 to 28 days according to previous studies (Ortega et al., 2014; Weber et al., 2012). At each collection time, an aliquot of $500 \mu \mathrm{L}$ of each sample was centrifuged 10 minutes at $16000 \mathrm{~g}$ and the supernatant was filtered through a $0.1 \mu \mathrm{m}$ syringe filter to eliminate remaining particles (Ortega et al., 2014). $100 \mu \mathrm{L}$ of supernatant were diluted in $\mathrm{HNO}_{3} 5 \%$ and analyzed by inductively coupled plasma mass spectrometry (ICP-MS, NexION 350X, PerkinElmer) equipped with an auto sampler and a crossflow nebulizer. The instrument was calibrated using $0.1,0.5,1,2,5,10$ and 20 parts per billion $(\mathrm{ppb})$ of cobalt. To determine the amount of total cobalt in each sample, an aliquot of $100 \mu 1$ of particles solution was collected at the beginning of the incubation, and analyzed by inductively coupled plasma mass spectrometry (ICP-MS after acid digestion with $30 \% \mathrm{HCl}$ followed by $65 \% \mathrm{HNO}_{3}$, as previously described (Ortega et al., 2014). Each experiment was performed at least in triplicate, each replicate being prepared from a different cobalt solution. The results were expressed as \% of solubilized cobalt (solubilized cobalt $v s$ total cobalt).

204

\section{Dissolution using the biphasic dynamic assay}

Agarose gels were prepared by dissolution of agarose powder type IIA (Sigma) as a $2.5 \%$ solution in physiological saline (140 mM NaCl, $5 \mathrm{mM} \mathrm{KCl}, \mathrm{pH}$ 5.6), ALF or Gamble's solutions as described (Van der Meeren et al., 2019). The agarose solution was melted by heating in a microwave, and $\mathrm{Co}_{3} \mathrm{O}_{4} \mathrm{P}$ were 
was used whatever the molecules, alone or in combination. The agarose solution was then distributed in

211

212

24 well-culture dishes, representing the static phase. After the gel had hardened, the dynamic phase was added in the wells. The plates were then incubated at $37^{\circ} \mathrm{C}$ in a $5 \% \mathrm{CO}_{2}$ atmosphere on an orbital shaker. At the end of the experiment, the samples were collected, digested with concentrated ultrapure chlorhydric and nitric acid. Digested samples were diluted in $\mathrm{HNO}_{3} 1 \%$ and analyzed using ICP-MS (NexION 350X, PerkinElmer or ICAPQ Thermo). The calibration was conducted with $0.1,0.5,2,10$, 20, $50 \mu \mathrm{g} / \mathrm{L}$ standards prepared in $\mathrm{HNO}_{3} 1 \%$. Gallium (Analab) was used as internal standard. All conditions were done in triplicate.

The principle of the biphasic assay is based on the hypothesis that bioavailable ions would migrate into the dynamic fluid phase, while particles or complexes formed with biological ligands would remain trapped in the static phase. The validation of our assay was done using actinides (Griffiths et al., 2016; Van der Meeren et al., 2019). To ensure that it was also applicable to cobalt, we compared the transferability of different chemical forms of cobalt incorporated in the gel. Our results (shown in Figure S1) demonstrate the low retention of $\mathrm{CoCl}_{2}$ in the static phase (20\% in 7 days) as opposed to the high retention of particles ( $>99 \%$ on 7 days). In addition, to make sure that only $\mathrm{Co}^{2+}$ ions were transferred in the dynamic phase following the dissolution of particles, the dynamic phase was filtered through 100 $\mathrm{nm}$ diameter pore filters. Cobalt concentrations measured in the filtered samples did not differ from those of the non-filtered samples (data not shown).

\section{Statistical Analysis}

Results are expressed as mean $\pm \mathrm{SD}$. One-way ANOVA followed by Dunnett's multiple comparisons test were performed using GraphPad Prism version 8 (GraphPad Software; La Jolla, CA, USA).

\section{Results}

\section{1/Intrinsic $\mathrm{Co}_{3} \mathrm{O}_{4} \mathrm{P}$ dissolution rate in $\mathrm{NaCl}$, Hepes, $\mathrm{ALF}$ and Gamble's.}

We first evaluated the intrinsic dissolution properties of $\mathrm{Co}_{3} \mathrm{O}_{4} \mathrm{P}$ in $\mathrm{HEPES}$ and $\mathrm{NaCl} / \mathrm{KCl}$, for a 7 -day incubation period. Next, Gamble's solution and ALF were used, as the common surrogate fluids of the 
A

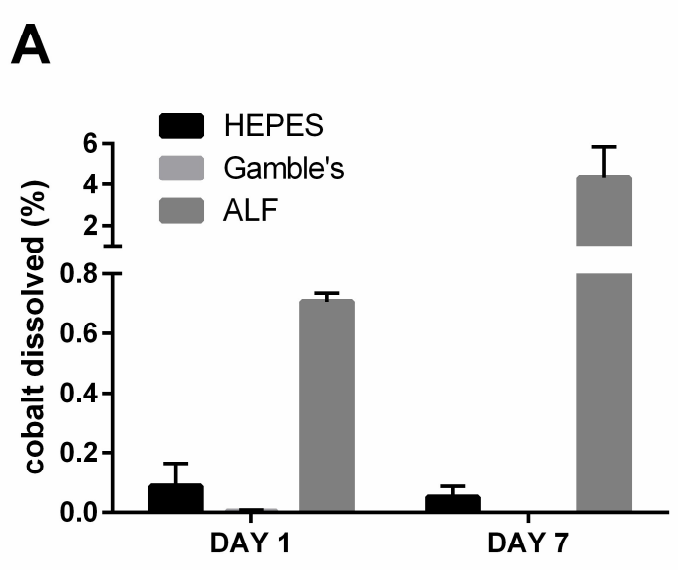
2011).
B

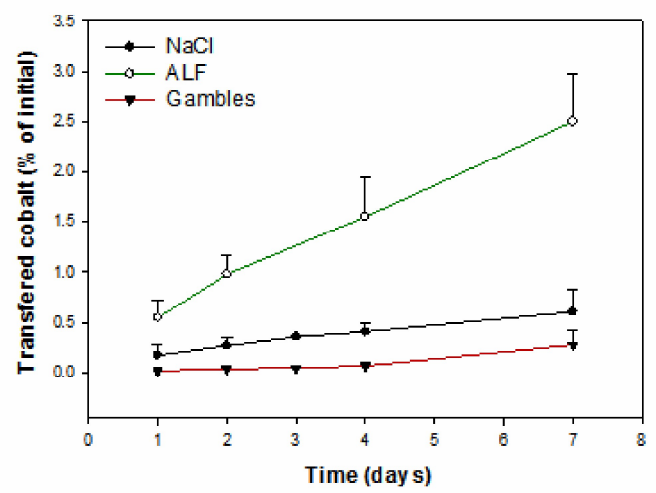

247

main lung retention compartments. Gamble's solution mimics the interstitial and airway lining fluids, whereas ALF simulates intracellular conditions in phagocytes, such as macrophages (Marques et al.,

A low solubility of $\mathrm{Co}_{3} \mathrm{O}_{4} \mathrm{P}$ was observed in the HEPES medium for which no interaction/complexation with ligands occurred. Less than $0.2 \%$ of $\mathrm{Co}^{2+}$ was released over the 7-day incubation period (Figure 1A). Dissolution was even lower in Gamble's, with less than $0.02 \%$ cobalt dissolution over 7 days. A significantly higher dissolution was observed in ALF, with $0.7 \%$ dissociated cobalt after a one-day incubation period and up to $4.3 \%$ after 7 days (Figure. 1A). Similar results were obtained with the biphasic dynamic assay although a lower dissolution was measured in ALF (2.6\% in 7 days) (Figure 1B). Both the presence of citrate and low $\mathrm{pH}$ could explain the higher dissolution in ALF.

\section{Figure 1: Dissolution of $\mathrm{Co}_{3} \mathrm{O}_{4} P$.}

$\mathrm{Co}_{3} \mathrm{O}_{4} P$ dissolution was assessed in solution. (A), $\mathrm{Co}_{3} \mathrm{O}_{4} P$ particles were incubated 1 day and 7 days, in HEPES, Gamble's and ALF. Results are expressed as mean \% $1 S D$ of solubilized Co versus total cobalt. In the two-phase dynamic assay, (B), $\mathrm{Co}_{3} \mathrm{O}_{4} \mathrm{P}$ were included in gels prepared in $\mathrm{NaCl} / \mathrm{KCl}, \mathrm{ALF}$ or Gamble's. Results are expressed as mean \% \pm SD of cumulative Co measured in the dynamic phase versus initial Co in the gel. Each experimental condition was done in triplicate and repeated 3 times.

\section{2/ Molecules showing $\mathrm{Co}^{2+}$-decorporating efficacy: effect on $\mathrm{Co}_{3} \mathrm{O}_{4} \mathrm{P}$ dissolution}

Various molecules, all being $\mathrm{Co}^{2+}$ - ligands with different affinities (Table S1), have shown some efficacy for decorporation of soluble forms of cobalt in rats (Levitskaia et al., 2011; Levitskaia et al., 2010b; Llobet et al., 1986, 1988). However, none of these molecules have been tested for decorporation of poorly soluble $\mathrm{Co}_{3} \mathrm{O}_{4} \mathrm{P}$. Therefore, using the dissolution assay in solution, we evaluated the ability of 
these ligands to increase $\mathrm{Co}_{3} \mathrm{O}_{4} \mathrm{P}$ dissolution in the lung fluids surrogates Gamble's and ALF, as well as

261

262

263

264

265

266

267

268

269

270

271

272
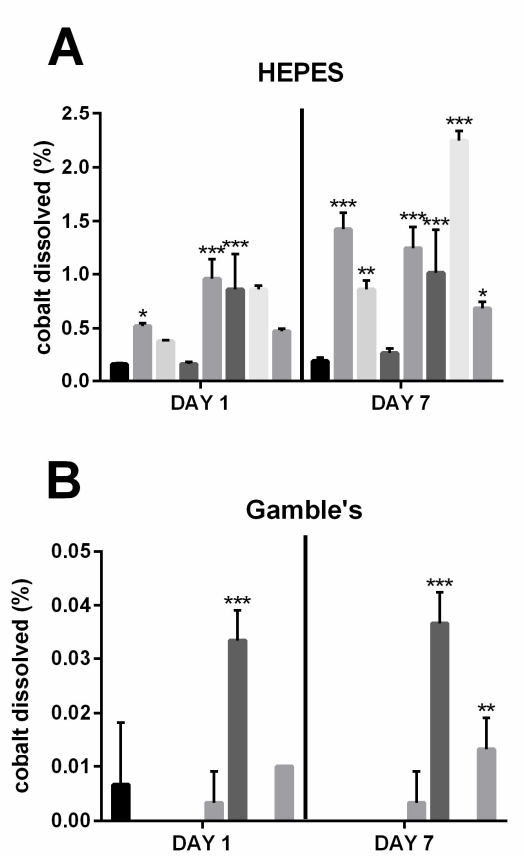
Giampreti et al., 2016). (Figure 2C) as compared to the untreated controls.

in HEPES. The efficacy of the different drugs N-acetyl-L-cysteine (NAC), EDTA, L-cysteine (L-cys), glutathione (GSH), N,N-bis (2-aminoethyl) -1,2-ethanediamine dihydrochloride (Trien) and Dpenicillamine (D-PEN) was assessed and compared to that of DTPA, as DTPA is currently the recommended treatment in case of accidental internal contamination with $\mathrm{Co}_{3} \mathrm{O}_{4} \mathrm{P}$ (ASN, 2008;

In HEPES, a statistically significant increase in $\mathrm{Co}_{3} \mathrm{O}_{4} \mathrm{P}$ dissolution was observed at day 7 with all the tested molecules except TRIEN (Figure 2A). The highest efficacy was obtained with EDTA leading to $2.2 \%$ dissolution $(p<0.001)$ at day 7 . In contrast, none of the tested molecules induced a statistically significant increase in $\mathrm{Co}_{3} \mathrm{O}_{4} \mathrm{P}$ dissolution in Gamble's except the two sulphur-containing molecules, Lcys and to a lower extent GSH (Figure 2B). However, the percentage of $\mathrm{Co}_{3} \mathrm{O}_{4} \mathrm{P}$ dissolution remained very low $(<0.05 \%)$. In ALF, no increase in particle dissociation was observed whatever the drug tested 

$(\mathrm{p}<0.001)$ at day 4.

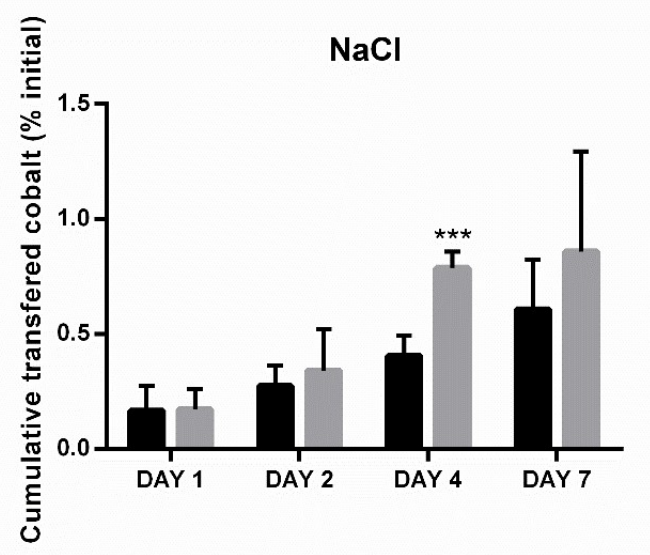

Control
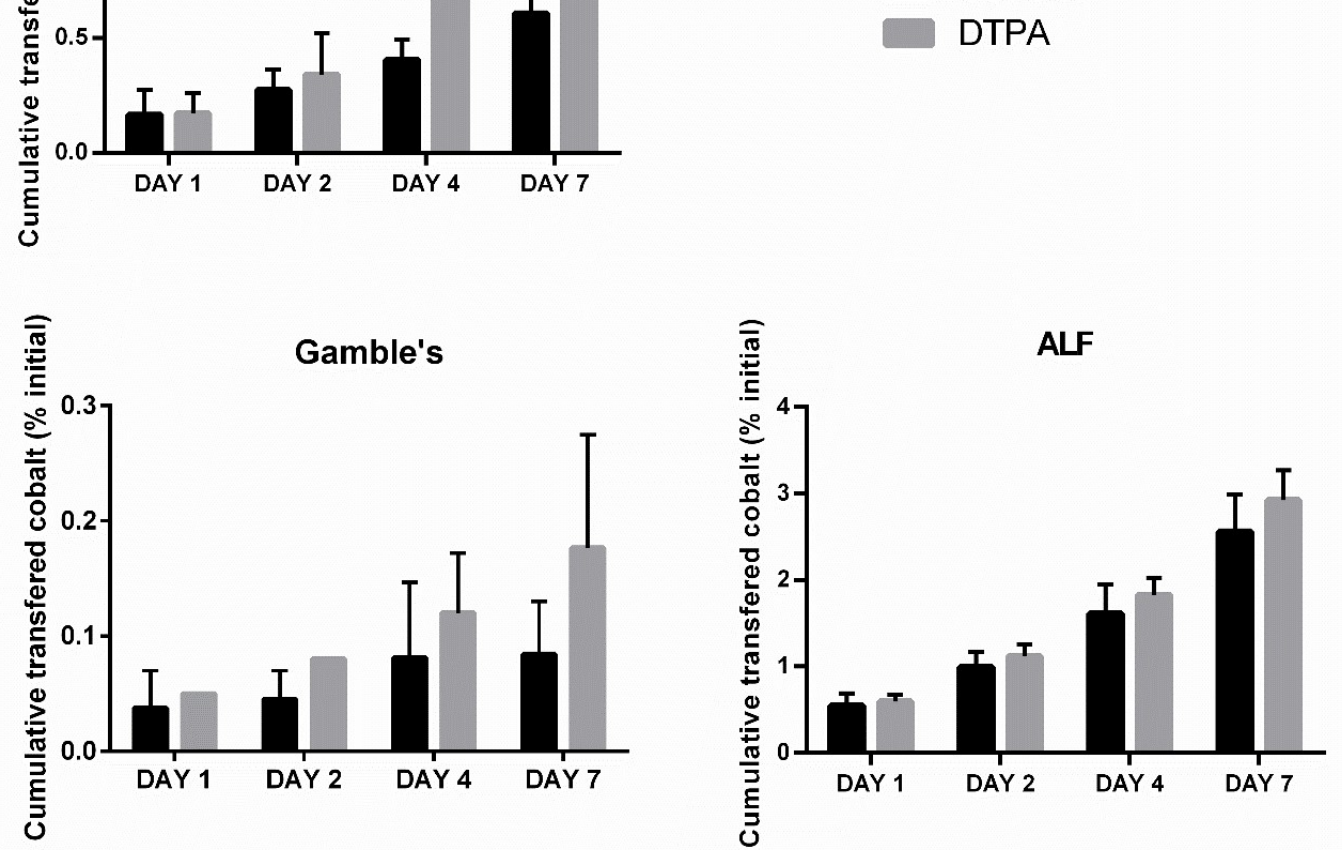

284

Figure 3: Effect of DTPA on the dissolution of $\mathrm{Co}_{3} \mathrm{O}_{4} \mathrm{P}$ assessed in the two-phase dynamic assay. $\mathrm{Co}_{3} \mathrm{O}_{4} \mathrm{P}$ were included in the static retention phase (agarose gels) prepared in $\mathrm{NaCl}$, Gamble's or ALF. $D T P A 500 \mu M$ was added in the dynamic phase. Results are expressed as mean $\% \pm S D$ of cumulative cobalt transferred in the dynamic phase/initial cobalt in the gel. Each experimental condition was done in triplicate and repeated 1 to 3 times. ${ }^{* *} p<0.001$.

The contrasting results obtained using both assays in the non-physiologic buffers and in the lung surrogates (Gamble's and ALF) highlight the importance of using biologically-relevant media for dissolution studies, as also previously reported by others (Kastury et al., 2017). 
297 The absence of effect of the above tested molecules on $\mathrm{Co}_{3} \mathrm{O}_{4} \mathrm{P}$ dissolution in lung fluid surrogates is

298 likely to predict a low decorporation efficacy of those drugs following pulmonary contamination with

$299 \mathrm{Co}_{3} \mathrm{O}_{4} \mathrm{P}$.

300 Therefore, from an exhaustive review of the literature summarized in Table 1, we selected various

301 molecules with metal chelating properties as well as molecules enhancing other metal oxide particle

302 dissolution.

303 Table 1: Literature review of molecules involved in metal oxide dissolution

\begin{tabular}{|c|c|c|c|}
\hline Acting molecule & Metal (form) & Chemical effect & Reference \\
\hline Ascorbate & $\begin{array}{c}\mathrm{Fe}\left(\mathrm{Fe}_{2} \mathrm{O}_{3}, \mathrm{Fe}_{3} \mathrm{O}_{4}\right) \\
\text { Mn oxides }\end{array}$ & $\begin{array}{c}\text { Redox, chelation } \\
\text { Reductive dissolution }\end{array}$ & $\begin{array}{c}\text { Huang et al. } 2017 \\
\text { Joseph et al. } 1996 \\
\text { Afonso et al. } 1990 \\
\text { Suter et al. } 1991 \\
\text { Panias et al. } 1996 \\
\text { Stone et al. } 1984\end{array}$ \\
\hline Ascorbate + EDTA & $\mathrm{Fe}\left(\mathrm{Fe}_{2} \mathrm{O}_{3}, \mathrm{Fe}_{3} \mathrm{O}_{4}\right)$ & $\begin{array}{l}\text { Auto accelerated } \\
\text { reductive dissolution }\end{array}$ & Afonso et al. 1990 \\
\hline Ascorbate + oxalate & $\mathrm{Fe}\left(\mathrm{Fe}_{2} \mathrm{O}_{3}, \mathrm{Fe}_{3} \mathrm{O}_{4}\right)$ & $\begin{array}{l}\text { Reductive dissolution } \\
\text { and chelation }\end{array}$ & Afonso et al. 1990 \\
\hline Catechols & Mn oxides & $\begin{array}{l}\text { Reduction and } \\
\text { chelation }\end{array}$ & Stone et al. 1984 \\
\hline Citrate & $\mathrm{Fe}\left(\mathrm{Fe}_{2} \mathrm{O}_{3}\right)$ & $\mathrm{pH}$ & Joseph et al. 1996 \\
\hline $\begin{array}{c}\text { Combination CEA (citrate, } \\
\text { ascorbate, EDTA) }\end{array}$ & $\mathrm{Fe}\left(\mathrm{Fe}(\mathrm{III})_{2} \mathrm{O}_{3}\right)$ & $\begin{array}{l}\text { Ligand assisted } \\
\text { reductive dissolution }\end{array}$ & $\begin{array}{c}\text { Joseph et al. } 1996 \\
\text { Anathan et al. } 2003\end{array}$ \\
\hline DFOB & $\begin{array}{c}\mathrm{Co}(\mathrm{CoOOH}) \\
\text { Fe (oxides) } \\
\text { Fe (Cr(III)-Fe(III)- } \\
\text { (oxy)hydroxides) }\end{array}$ & Redox Chelation & $\begin{array}{c}\text { Bi et al. } 2010 \\
\text { Kraemer. } 2004 \\
\text { Saad et al. } 2017\end{array}$ \\
\hline DFOB + oxalate & $\begin{array}{c}\mathrm{Fe}(\mathrm{Cr}(\mathrm{III})-\mathrm{Fe}(\mathrm{III})- \\
\text { (oxy)hydroxides) } \\
\mathrm{Al}\left(\mathrm{Fe}_{3} \mathrm{O}_{4}\right)\end{array}$ & Redox, chelation & $\begin{array}{c}\text { Saad et al. } 2017 \\
\text { Cervini-Silva et al. } 2002\end{array}$ \\
\hline $\begin{array}{c}\text { DIPIC (2,6- } \\
\text { pyridinedicarboxylate) }\end{array}$ & $\mathrm{Co}(\mathrm{Co}(\mathrm{II}), \mathrm{Co}(\mathrm{III}))$ & Chelation & Yang et al. 2002 \\
\hline enterobactin & $\mathrm{Fe}(\mathrm{Fe}-\mathrm{OOH})$ & $\begin{array}{c}\text { Ligand metal affinity } \\
\text { and adsorbtion }\end{array}$ & Dubbin et al. 2017 \\
\hline Ferrichrome & $\mathrm{Fe}(\mathrm{Fe}-\mathrm{OOH})$ & $\begin{array}{l}\text { Ligand metal affinity } \\
\text { and adsorbtion }\end{array}$ & Dubbin et al. 2017 \\
\hline HEDP & Co (II) & Ligand & Jurisson et al. 1983 \\
\hline Histidine & Co (II) & Ligand & Bornhost et al. 2000 \\
\hline Oxalate & Fe (oxides) & Redox, chelation & $\begin{array}{c}\text { Kraemer. } 2004 \\
\text { Panias et al. } 1996 \\
\text { Zinder et al. } 1986 \\
\end{array}$ \\
\hline $\begin{array}{c}\text { phenolic reductants } \\
\text { (catechol) }\end{array}$ & $\mathrm{Fe}\left(\mathrm{FeOOH}, \mathrm{Fe}_{2} \mathrm{O}_{3}\right)$ & redox & Lakind et al. 1989 \\
\hline Tannic acid & $\mathrm{Cu}$ (CuO NPs) & chelation & Zhao et al. 2017 \\
\hline
\end{tabular}


305 A total of 32 assays were carried out using the dissolution assay in solution for efficacy testing of a total 306 of 21 molecules and 11 different combinations. This screening was done in Gamble's and ALF given 307 the lack of consistency between results obtained in HEPES saline solution and lung fluid surrogates. $308 \mathrm{Co}^{2+}$ was measured at days 1 and 7 (Table 2). For ALF, in the absence of added molecules, the percentage 309 of dissolution differed between experiments (from 0.57 to $0.85 \%$ at day 1 and from 2.9 to $4.9 \%$ at day 310 7). Therefore, to allow a comparative evaluation of dissolution efficacy in ALF, we used the percentage 311 of dissolution measured in the presence of the molecule tested divided by the percentage of dissolution 312 observed in the related control, to calculate a ratio. This calculation mode was not necessary for results 313 obtained in Gamble's, because of lower day variability. Thus, results obtained in Gamble's were 314 expressed as \% of solubilized cobalt/ total cobalt content.

315 The tested molecules were classified in different categories: $\mathrm{Co}^{2+}$ - ligands, high SH-containing ligands 316 and molecules enhancing metal oxide dissolution. Association of molecules from these categories were 317 also tested (Table 2). Our results will be described in the following paragraphs, according to the category 318 of the tested molecules. 
Table 2: Dissolution of $\mathrm{Co}_{3} \mathrm{O}_{4} \mathrm{P}$ in the presence of various molecules assessed in Gamble's and $A L F$ using the dissolution assay in solution.

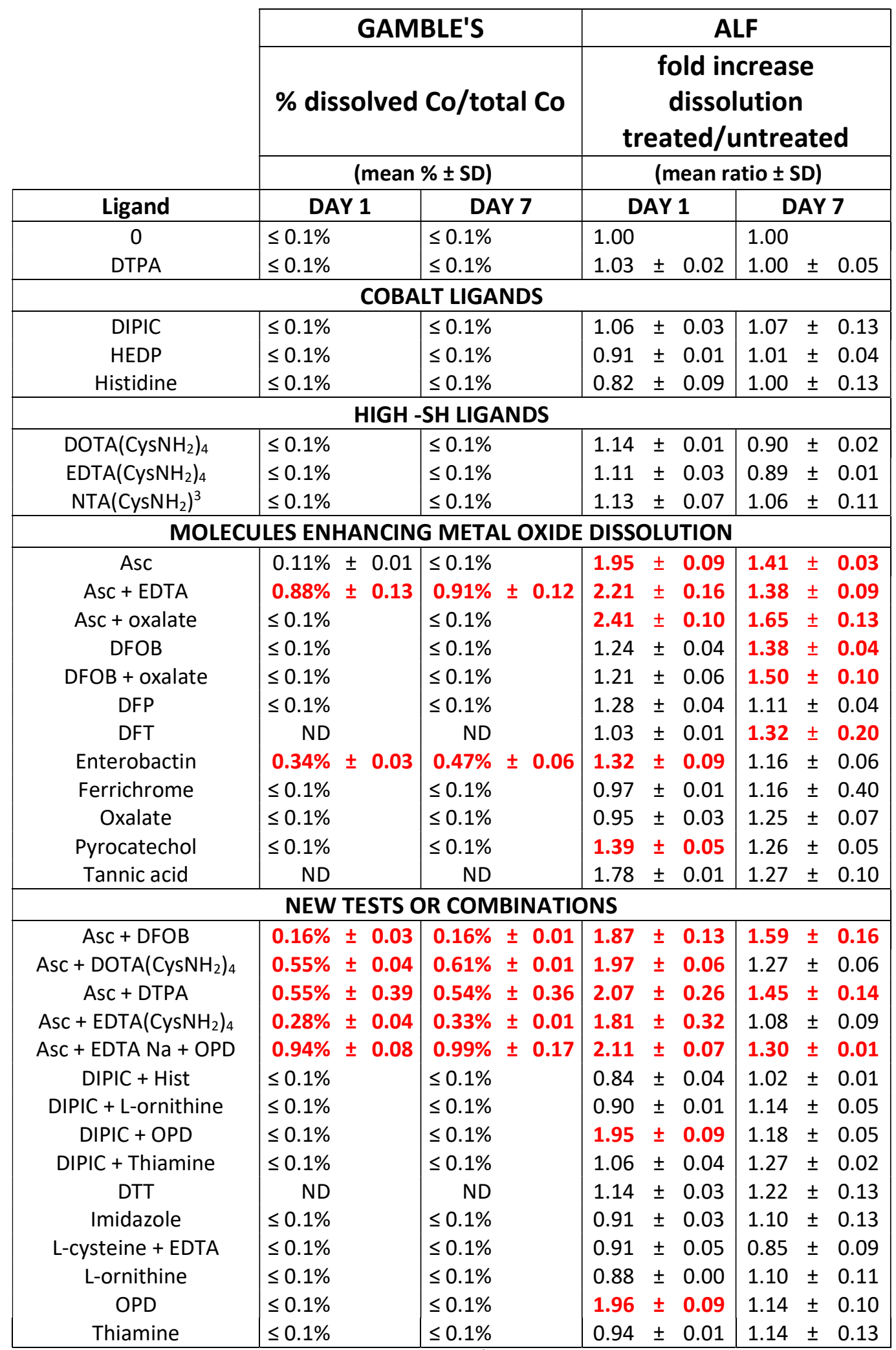


$A L F$, to allow a comparative evaluation of dissolution efficacy, we used the percentage of dissolution measured in the presence of the molecule tested divided by the percentage of dissolution observed in the related control, to calculate a ratio. Results are expressed as mean \pm sd. Ratios above 1.3 are shown in red and bold characters. ND: not determined

\section{1/ Effect of cobalt ligands and $\mathrm{SH}-$ rich ligands on $\mathrm{Co}_{3} \mathrm{O}_{4} \mathrm{P}$ dissolution}

The first category of selected molecules included cobalt ligands listed in Table 1.Both histidine, DIPIC (2,6-pyridinedicarboxylate) and HEDP (1-Hydroxyethylidenediphosphonic acid) are known $\mathrm{Co}^{2+}-$ ligands (Bornhorst and Falke, 2000; Jurisson et al., 1983; Yang et al., 2002). In our hands, these molecules had no influence on $\mathrm{Co}_{3} \mathrm{O}_{4} \mathrm{P}$ dissolution neither in Gamble's nor in ALF (Table 2).

The second category of chosen molecules were SH-rich ligands, since sulfur-containing molecules, i.e L-cys and NAC induced a low but significant increase in $\mathrm{Co}_{3} \mathrm{O}_{4} \mathrm{P}$ dissolution in Gamble's (Figure 2). We synthesized sulphur pseudopeptides bearing a larger number of sulphur atoms in their chelating scaffolds, in an attempt to enhance the dissolution effect observed in Gamble's with the monothiol molecules. These sulfur-containing pseudopeptides are polydentate ligands built on NTA, EDTA and DOTA, grafted which three to four cysteines. The structures of the three pseudopeptides are reported in Scheme $\mathrm{S} 1$ together with their affinity for $\mathrm{Co}^{2+}$ measured at physiological $\mathrm{pH}$. $\mathrm{NTA}\left(\mathrm{CysNH}_{2}\right)_{3}$ is a trithiol ligand previously designed for metal chelation, demonstrating a large affinity for $\mathrm{Cu}^{+}$and to a lesser extent for $\mathrm{Zn}^{2+}$ (Pujol et al., 2009, 2011). It forms a CoL complex with a micromolar affinity at $\mathrm{pH} 7.4$, which is significantly larger than the affinities reported for $\mathrm{Co}^{2+}$ with L-cys and GSH (Table S1). The two other pseudopeptides derived from EDTA and DOTA. EDTA(CysNH$)_{4}$ and $\operatorname{DOTA}\left(\mathrm{CysNH}_{2}\right)_{4}$, that were specifically designed for this study, have four thiolates in their structure. As expected, their affinity for $\mathrm{Co}^{2+}$ is larger than with $\mathrm{NTA}\left(\mathrm{CysNH}_{2}\right)_{3}$ since $\mathrm{Co}^{2+}$ is known to be efficiently coordinated in a tetrahedral tetrathiolate coordination environment. Their CoL complexes exhibit stabilities in the nanomolar range at $\mathrm{pH} 7.4$, the cyclic DOTA derivative demonstrating a slightly larger affinity. It has to be noted that the two latter sulphur-rich ligands are able to complex a second $\mathrm{Co}^{2+}$ ion probably through the $\mathrm{N} / \mathrm{O}$ atoms of the chemical scaffold in a $\mathrm{Co}_{2} \mathrm{~L}$ complex.

However, despite their enhanced affinity for $\mathrm{Co}^{2+}$ with respect to monothiol molecules, none of these sulfur pseudopeptides led to an increased $\mathrm{Co}_{3} \mathrm{O}_{4} \mathrm{P}$ dissolution whatever the medium used (Table 2). 
Since none of the molecules tested above were able to induce significant increase in the dissolution of $\mathrm{Co}_{3} \mathrm{O}_{4} \mathrm{P}$, we selected other molecules from literature (Table 1) which, alone or in combination, have been shown to induce a strong dissolution of metallic oxides particles of iron, copper, or manganese. We also tested the effect of ligands susceptible of releasing protons, since protons (or low $\mathrm{pH}$ ) have a strong effect on metallic oxide particle dissolution.

The role of metal ion reduction on particle dissolution has been demonstrated with ascorbate (Afonso et al., 1990; Huang et al., 2017; Joseph et al., 1996; Panias et al., 1996; Stone and Morgan, 1984; Suter et al., 1991), oxalate (Kraemer, 2004; Panias et al., 1996; Zinder et al., 1986) and with phenolic reductants as catechol (Lakind and Stone, 1989) or tannic acid (Zhao et al., 2017). These compounds have been shown to increase the dissolution of metal oxides, such as Fe and Mn by reduction. Some of these molecules seem to act through combined reductive and metal-binding effects. Moreover, association of different kinds of molecules was shown to induce efficient particle dissolution, such as ascorbate with oxalate or EDTA as well as with a mixture of citric acid and EDTA (Afonso et al., 1990; Joseph et al., 1996). It should be mentioned that all these studies were performed in non-physiologic buffers and mainly at acidic $\mathrm{pH}(\leq 4)$. In the present study, tannic acid, pyrocathecol and ascorbate alone or in association with oxalate or with EDTA significantly enhanced $\mathrm{Co}_{3} \mathrm{O}_{4} \mathrm{P}$ dissolution in ALF. The highest efficacy was obtained with the association of ascorbate and oxalate (2.41 fold increase as compared to controls at day 1 and 1.65 fold at day 7, these ratios corresponding respectively to 1.6 and $5.2 \%$ of dissolution). However, this association had no effect in Gamble's. The association of ascorbate and EDTA increased significantly the dissolution of $\mathrm{Co}_{3} \mathrm{O}_{4} \mathrm{P}$ in both lung fluid surrogates, reaching $0.91 \%$ dissolution in Gamble's and a ratio to a 1.38 fold increase as compared to controls in ALF at day 7 (Table 2 ). It is interesting to keep in mind that citrate is one of the components of ALF. Except for the combination of ascorbate and EDTA, no other significant increase in $\mathrm{Co}_{3} \mathrm{O}_{4} \mathrm{P}$ dissolution was observed in Gamble's (Table 2).

379 Siderophore-promoted dissolution has also been described for iron oxides. Dubbin et al., described an increase in iron release from synthetic goethite in the presence of ferrichrome and enterobactin at $\mathrm{pH}$ 6.5 (Dubbin and Bullough, 2017). Desferrioxamine B (DFOB) has been shown to increase Fe release 
from $\mathrm{Cr}$ (III)-Fe(III)-(oxy)hydroxides in an HEPES buffer at pH 7, and oxalate acted synergistically with DFOB to increase the Fe release (Saad et al., 2017). Bi et al demonstrated the solubilizing effect of DFOB on heterogenite in a $\mathrm{pH}$ dependent manner (Bi et al., 2010). We thus tested four siderophores: DFOB, enterobactin, desferrithiocin (DFT) and deferiprone (DFP). In Gamble's, only enterobactin induced an increase in $\mathrm{Co}_{3} \mathrm{O}_{4} \mathrm{P}$ dissolution $(0.47 \%$ dissolution at day 7$)$. In $\mathrm{ALF}$, both enterobactin and DFOB slightly enhanced dissolution. DFOB induced a 1.38 fold higher dissolution than that of controls at day 7, which is consistent with published data obtained for heterogenite particles (Bi et al., 2010). The two other siderophores, DFT and DFP also increased the dissolution of $\mathrm{Co}_{3} \mathrm{O}_{4} \mathrm{P}$ in ALF but to a lesser extent than DFOB (Table 2).

Saad et al. demonstrated that siderophore and oxalate promoted dissolution of $\mathrm{Cr}(\mathrm{III})-\mathrm{Fe}(\mathrm{III})-$ (oxy)hydroxides (Saad et al., 2017). By using this combination, we reached a 1.5 increase in $\mathrm{Co}_{3} \mathrm{O}_{4} \mathrm{P}$ dissolution in ALF at day 7 as compared to the controls, which makes this combination one of the best candidates (Table 2).

\section{3/ Effect of novel molecule associations on $\mathrm{Co}_{3} \mathrm{O}_{4} \mathrm{P}$ dissolution}

Altogether, the above reported results highlight the improved efficacy of associations of molecules with complementary properties such as metal reduction and strong $\mathrm{Co}^{2+}$-binding properties as compared to each molecule alone. We thus tested molecules not reported in the literature for metal oxides dissolution but for which intrinsic properties might enhance the dissolution of cobalt particles.

We first tested dithiothreitol (DTT) for its strong reducing properties. Howewver, DTT showed a lower efficacy to dissociate $\mathrm{Co}_{3} \mathrm{O}_{4}$ particles than ascorbate in ALF (Table 2). In contrast, L-Cys, which is also a reductant, was shown to slightly increase $\mathrm{Co}_{3} \mathrm{O}_{4} \mathrm{P}$ dissolution in Gamble's (Figure 2B). Thus, we evaluated the efficacy of a combination of ascorbate or L-Cys and high affinity $\mathrm{Co}^{2+}$ ligands (Table 2). The combination of L-cys with EDTA did not improve $\mathrm{Co}_{3} \mathrm{O}_{4} \mathrm{P}$ dissolution. Therefore, we focused on combinations involving ascorbate and cobalt ligands with different coordinating atoms and affinities (Table S1).

We did not observe any significant synergistic effect between ascorbate and DFOB. In contrast, the addition of ascorbate to the SH-rich pseudopeptides DOTA(Cys) ${ }_{4}$ and EDTA(Cys) $)_{4}$ led to $0.61 \%$ and 
$0.33 \%$ dissolution respectively at day 7 in Gamble's, showing a good synergistic effect as compared to

411

412 each molecule used alone. This effect was not observed in ALF. In Gamble's we observed a strong synergistic effect with ascorbate and DTPA as compared to DTPA alone with $0.54 \%$ of dissolution at day 7 versus $<0.1 \%$ for DTPA alone. This was not the case in ALF.

The combination of ascorbate with EDTA was one of the most effectives in Gamble's, with $0.91 \%$ of dissolution at day 7. Since the affinity of DTPA for $\mathrm{Co}^{2+}$ is larger than that of EDTA (Table 1. Sup mat), the affinity for $\mathrm{Co}^{2+}$ does not seem to be the determining factor for an effective dissolution of $\mathrm{Co}_{3} \mathrm{O}_{4} \mathrm{P}$ in the lung fluid surrogates.

$\mathrm{pH}$ or the ability to deliver protons at the particle surface has also been reported as important factors in particle dissolution. A low $\mathrm{pH}$ however may prevent efficient chelation of $\mathrm{Co}^{2+}$ by chelating groups with mid or high pKA values. Dipicolinic acid (DIPIC) was shown to be of interest, as the $\left[\mathrm{Co}(\text { dipic })_{2}\right]^{2-}$ complex is stable even at low $\mathrm{pH}$ due to the low basicity of the nitrogen atom found in the aromatic heterocycle (Yang et al., 2002). In addition, combination of DIPIC with proton acceptors (histidine, thiamine, ornithine and o-phenylenediamine, OPD) were described to enhance and stabilize the formation of the $\left[\mathrm{Co}(\text { dipic })_{2}\right]^{2-}$ complexes at low $\mathrm{pH}$ (Ghasemi et al., 2014). However, no significant effect of these combinations was observed on the dissolution of $\mathrm{Co}_{3} \mathrm{O}_{4} \mathrm{P}$ in Gamble's or in ALF (Table 2). In contrast, OPD alone had a slight effect in ALF. Therefore, we also tested OPD in combination with ascorbate and EDTA. OPD addition significantly increased $\mathrm{Co}_{3} \mathrm{O}_{4} \mathrm{P}$ dissolution efficacy in Gamble's, with a dissolution ratio of $0.94 \%$ and $0.99 \%$ at day 1 and day 7 , respectively, but not in ALF. Whereas it should be noted that addition of OPD markedly increased the efficacy of ascorbate and EDTA, those combinations were not retained for the rest of the study due to the toxicity of OPD (Matsumoto et al., 2012).

In summary, the best combinations of molecules are: ascorbate alone, DFOB alone and the combination of ascorbate with EDTA, ascorbate with oxalate, ascorbate with DTPA, ascorbate with DFOB and DFOB with oxalate. 


\section{4/ Influence of ligand concentration on $\mathrm{Co}_{3} \mathrm{O}_{4} \mathrm{P}$ dissolution.}

439 We studied then the impact of DTPA or EDTA concentration in both lung fluids when used in

440

441

442

443

444

445

446

447

association with ascorbate. Indeed, a strong effect of EDTA concentration on the dissolution of hematite in citric acid-EDTA-ascorbic acid mixtures has been previously observed (Joseph et al., 1996). The concentration of EDTA and DTPA was increased up to $50 \mathrm{mM}$. Whereas this high concentration has no physiological relevance, this study was made to identify the importance of $\mathrm{Co}^{2+}$-chelation in the dissolution process. By increasing 100 fold the EDTA concentration $(50 \mathrm{mM})$, the percentage of dissolution increased by a factor of 5 (from $0.8 \%$ to $4 \%$ ) in 7 days in Gamble's (Figure 4). In ALF, only a slight but significant increase was observed. These results are in agreement with what was described with hematite in citric acid-EDTA-ascorbic acid mixtures (Joseph et al., 1996). Noticeably, raising DTPA concentration led to only a moderate increase in $\mathrm{Co}_{3} \mathrm{O}_{4} \mathrm{P}$ dissolution in Gamble's. The decrease in dissolution observed in ALF as compared to the lower DTPA concentration of $0.5 \mathrm{mM}$, suggests different mechanisms of action for the two ligands.
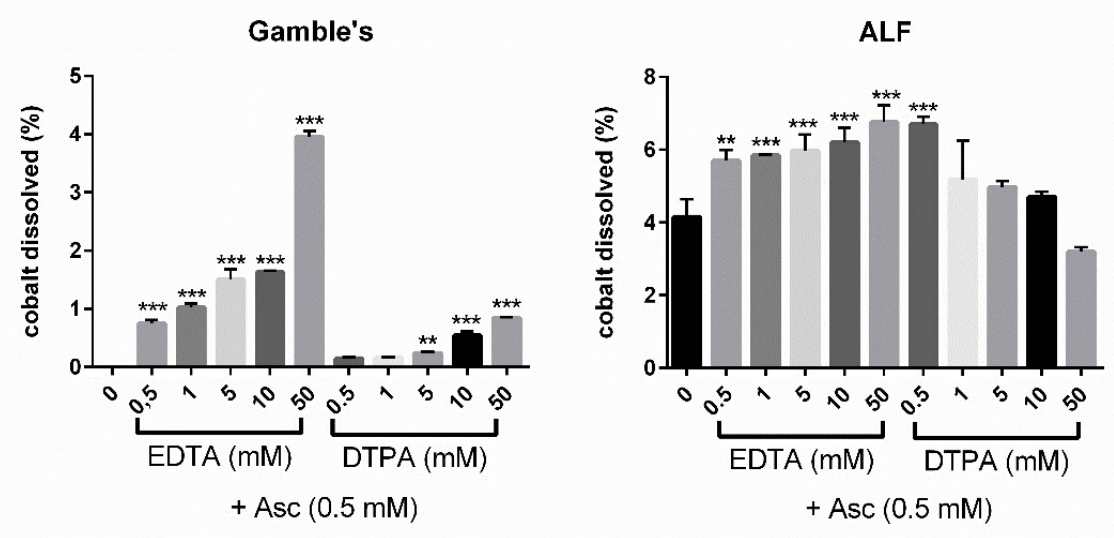

Figure 4: Impact of ligand concentration on particle dissolution at day 7 in Gamble's and ALF. Cobalt concentration remained constant while the ligand concentrations were increased from 0.5 to 50 $m M$, leading to ligand:cobalt ratios varying from 0.5 to 50 respectively. Results are expressed as mean $\% \pm S D$ of dissolved cobalt/ total cobalt content. $n=3$. Statistically significant differences from control were determined by one-way ANOVA followed by Dunnett's multiple comparisons test: ${ }^{*} p<0.05,{ }^{*} p$ $<0.01,{ }^{* *} p<0.001$.

\section{4/ Long-term effect of various combinations on $\mathrm{Co}_{3} \mathrm{O}_{4} \mathrm{P}$ dissolution.}

To evaluate the long-term effect, the dissolution assay with the best combination of molecules was conducted in solution over 28 days,. This could confirm the interest of chronic decorporation treatment 

Muggenburg, 1993).

Our results show that increasing the incubation time further increased $\mathrm{Co}_{3} \mathrm{O}_{4} \mathrm{P}$ dissolution for most of the conditions in Gamble's and for all in ALF. Ascorbate with EDTA $50 \mathrm{mM}$, in Gamble's, led to 8.2 $+/-1.8 \%$ dissolution although in the controls, soluble cobalt remained barely detectable (Figure 5). In ALF, although the $\mathrm{Co}_{3} \mathrm{O}_{4} \mathrm{P}$ dissolution in the controls was already of $18+/-3 \%$ in 28 days, the dissolved fraction was much larger and reached $48+/-8 \%, 43+/-1 \%$ and $40+/-10 \%$ with the ascorbate and particularly in presence of DFOB.
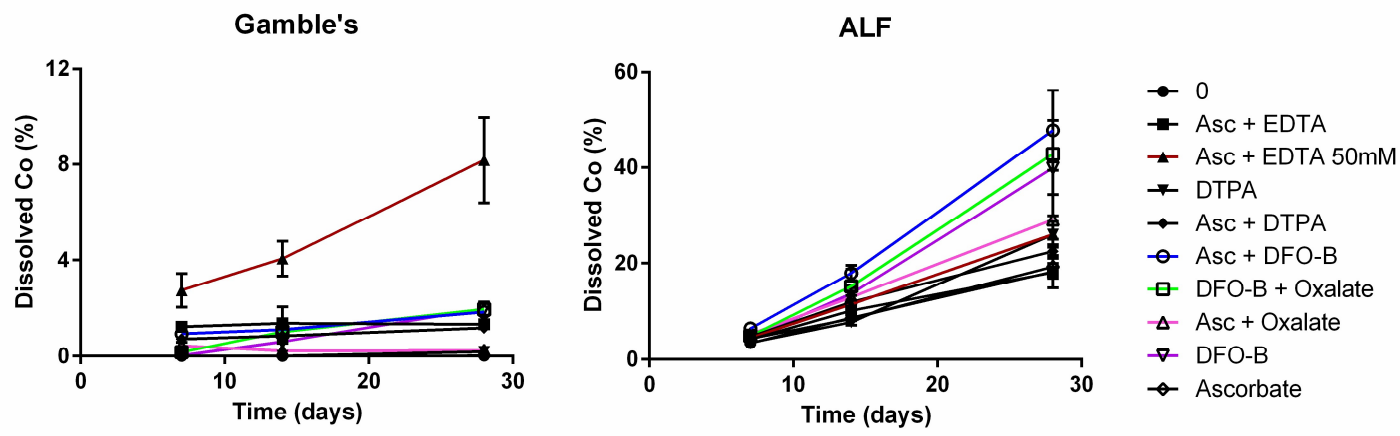

472

Figure 5: Dissolution of $\mathrm{Co}_{3} \mathrm{O}_{4} P$ up to 28 days incubation with selected ligand combinations.

Since $48 \%$ of the cobalt was released from particulate matter after an incubation period of 28 days by ascorbate and DFOB in ALF, a decrease in particle size was expected to occur. Indeed, TEM analysis showed that the mean size of particles was significantly smaller when incubated in ALF for 28 days in the presence of ascorbate and DFOB as compared to controls in ALF alone (mean size $129+/-59 \mathrm{~nm}$ vs $157 \pm 69 \mathrm{~nm}, \mathrm{p}<0.01$ ), (Figure 6). 
A

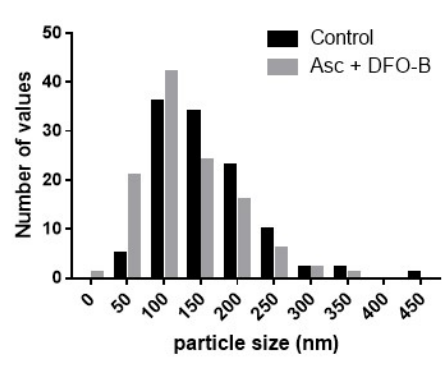

B

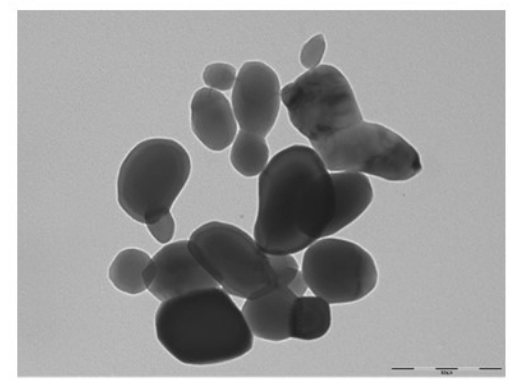

483

484

485

486

487

488

489

490

491

492

493

494

495

496

497

498

499

500

501

502

503

504

Figure 6: $\mathrm{Co}_{3} \mathrm{O}_{4} P$ size after a 28 day incubation with ascorbate and $\mathrm{DFOB}$.

A: TEM pictures were analyzed with Image $J$ software to determine the diameter of particles in each sample $(n=113)$. B: representative TEM picture of $\mathrm{Co}_{3} \mathrm{O}_{4} \mathrm{P}$ after a 28-day incubation with ascorbate and $D F O B$.

\section{5/ Validation of the results using the two-phase model}

To go further in the determination of efficacy of various drugs to enhance particle dissolution, we used the dynamic two-phase model assay to assess the efficacy of molecules selected from the dissolution assay in solution. For this assay, the static phase representing the retention compartments was prepared in $\mathrm{NaCl}$, Gamble's or ALF. The molecules to be tested were added to the dynamic phase representing the transfer compartment.

Efficacy was assessed by measurement of Co in the dynamic phase from 1 to 7 days after incubation in saline or lung surrogates. $\mathrm{Co}_{3} \mathrm{O}_{4} \mathrm{P}$ dissolution was increased in the presence of ascorbate whether or not associated with other molecules (Figure 7). Oxalate did not increase dissolution of $\mathrm{Co}_{3} \mathrm{O}_{4} \mathrm{P}$ in ALF and Gamble's when used alone, nor improved the efficacy of ascorbate when used in association. DFOB used alone was able to increase the dissolution of $\mathrm{Co}_{3} \mathrm{O}_{4} \mathrm{P}$ whatever the composition of the agarose gels.

Remarkably, the higher efficacy, observed both in Gamble's and ALF, was obtained with the association of the reductant ascorbate with the chelating agents DTPA or EDTA. These results confirm those obtained with the dissolution assay in solution. 

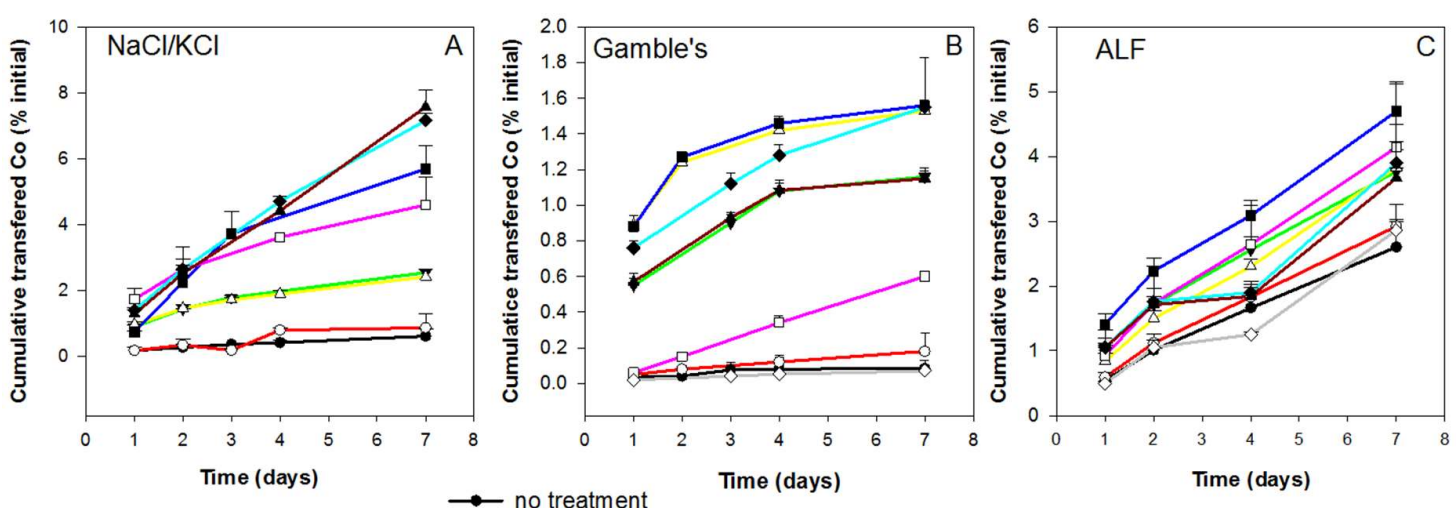

505

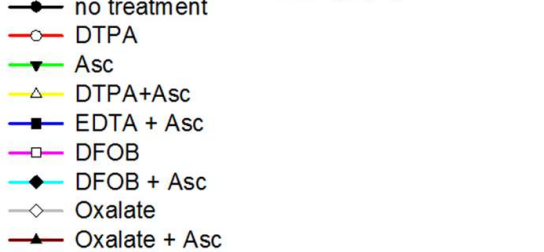

Figure 7: Effect of various molecules on dissolution of $\mathrm{Co}_{3} \mathrm{O}_{4} \mathrm{P}$ assessed in the two-phase dynamic assay.

$\mathrm{CO}_{3} \mathrm{O}_{4} \mathrm{P}$ were included in the static retention phase (agarose gels) prepared in $\mathrm{NaCl} / \mathrm{KCl}(7 \mathrm{~A})$, Gamble's (7B) or ALF (7C). Treatments $(500 \mu M)$ were added in the dynamic phase. Results are expressed as $\%$ cumulative cobalt measured in the dynamic phase/initial cobalt in the gel. Each experimental condition was done in triplicate and repeated 1 to 3 times.

As a summary, a schematic classification of the combinations with the highest efficacy at day 7 using both dissolution methods is presented in Table 3. Altogether, ascorbate associated with DTPA, EDTA and DFOB showed the highest efficacy on $\mathrm{Co}_{3} \mathrm{O}_{4} \mathrm{P}$ dissolution in both media.

Table 3: Schematic overview of the dissolution of $\mathrm{CO}_{3} \mathrm{O}_{4} \mathrm{P}$ in the presence of various molecules assessed in Gamble's and ALF at day 7.

\begin{tabular}{ccccccccc}
\hline & DTPA & Asc & DFOB & Ox & Asc/DTPA & Asc/EDTA & Asc/DFOB & Asc/ox \\
\hline \multirow{2}{*}{ Gamble's } & $=$ & + & + & $=$ & +++ & +++ & ++ & + \\
ALF & $=$ & + & ++ & $=$ & ++ & ++ & ++ & ++ \\
\hline
\end{tabular}

The combinations with highest efficacies in both media are shown in red. 


\section{Discussion}

525 Understanding the fate of poorly soluble inhaled compounds and the mechanisms controlling particle

526 retention and clearance from the lungs is essential to evaluate the risk of long-term exposure and to 527 develop tailored decorporation strategies. Following inhalation of poorly soluble compounds, such as

$528 \mathrm{Co}_{3} \mathrm{O}_{4} \mathrm{P}$, particle dissolution, occurring mainly in macrophages, represents the first step in lung 529 clearance. In case of inhalation of strong gamma emitters ${ }^{58} \mathrm{Co}$ or ${ }^{60} \mathrm{Co}$, the reduction of the retention

530 time is of crucial importance to avoid chronic irradiation of target cells. Once the ionic form $\mathrm{Co}^{2+}$ is

531 released by particle dissolution, it is expected to be rapidly eliminated from the body, mainly in urine.

532 Indeed clearance of almost $100 \%$ after injection of $\mathrm{CoCl}_{2}$ occurs in $45 \mathrm{~h}$ (Weber et al., 2012). To

533 accelerate urinary excretion, the use of chelating drugs is recommended. It is generally assumed that

534 ionic forms are more prompt to form complexes with biological ligands or chelating agents than

535 particulate forms, highlighting further the importance of increasing particle dissolution.

536 In the present study, our goal was to propose innovative strategies for $\mathrm{Co}_{3} \mathrm{O}_{4} \mathrm{P}$ dissolution, as a first step

537 of decorporating drug development. The novelty of our work is four fold: 1- the use of particles with

538 similar properties than those involved in a real accidental exposure at the work place, 2- the use of two

539 complementary in vitro dissolution assay, the second one showing good correlation with in vivo

540 excretion data following contamination with actinides, 3- the evaluation of efficacy of molecules

541 differing in their mechanisms of action and 4- the evaluation of efficacy on dissolution $\mathrm{Co}_{3} \mathrm{O}_{4} \mathrm{P}$, in

542 biologically-relevant conditions, representative of an inhalation scenario.

543 The dissolution assessment consisting in measuring the ionic fraction of cobalt in solution at different

544 times after incubation allowed the screening of a large number of molecules, used alone or in

545 combination in simple buffer as well as in lung fluid surrogates. On the other hand, the dissolution

546 assessment in the dynamic bi-compartmental assay, mimicking a retention phase and a transfer

547 compartment is expected to give a good correlation with in vivo data (Griffiths et al., 2016). Using these

548 two assays, we confirmed the low dissolution potential of $\mathrm{Co}_{3} \mathrm{O}_{4} \mathrm{P}$ in simple buffers, in the absence of

549 interactions with chemical or biological entities (Collier et al., 1992). Using lung fluids surrogates, we

550 showed that dissolution of $\mathrm{Co}_{3} \mathrm{O}_{4} \mathrm{P}$ was influenced by various parameters such as $\mathrm{pH}$ or the presence of 
compounds as citrate, carbonate, proteins, etc..., in line with results obtained for a number of metal oxide particles (Kastury et al., 2017; Pelfrene et al., 2017). The higher $\mathrm{Co}_{3} \mathrm{O}_{4} \mathrm{P}$ dissolution in ALF, representing the intracellular compartment of macrophages, likely results from the lower $\mathrm{pH}$ of this medium (pH 4.5 vs $\mathrm{pH} 7.4$ in HEPES and Gamble's) and the presence of citrate, since both parameters have been shown to facilitate dissolution of cobalt oxides (Collier et al., 1992; Lundborg et al., 1992). $\mathrm{Co}_{3} \mathrm{O}_{4} \mathrm{P}$ dissolution measured in the present study in ALF was of the same order of magnitude than previously reported (Cho et al., 2012; Collier et al., 1992; Ortega et al., 2014). The contrasting results obtained in buffers as compared to lung fluid surrogates, (Figures 2 and 3) underlined the need for using surrogates of relevant biological fluids for such studies.

We evaluated the efficacy of various molecules to increase $\mathrm{Co}_{3} \mathrm{O}_{4} \mathrm{P}$ dissolution, including DTPA as a gold standard, since this chelating agent is the recommended treatment following internal contamination with cobalt. In lung fluids, no dissolution enhancement was observed on $\mathrm{Co}_{3} \mathrm{O}_{4} \mathrm{P}$ dissolution with DTPA, nor in the presence of molecules previously described by others for their efficacy to decorporate soluble $\mathrm{Co}^{2+}$ (Figures 2 and 3). Further testing with specifically designed molecules with high-affinity for $\mathrm{Co}^{2+}$ or known $\mathrm{Co}^{2+}$ binding molecules (listed in Table 1) did not improve $\mathrm{Co}_{3} \mathrm{O}_{4} \mathrm{P}$ dissolution either. In addition, since the affinity of DTPA for $\mathrm{Co}^{2+}$ is larger than that of EDTA (Table 1. Sup mat), and the $\mathrm{Co}_{3} \mathrm{O}_{4} \mathrm{P}$ dissolution less efficient with DTPA than EDTA, the affinity for $\mathrm{Co}^{2+}$ does not seem to be the determining factor for an effective dissolution of $\mathrm{Co}_{3} \mathrm{O}_{4} \mathrm{P}$ in the lung fluid surrogates. These result strongly suggest that chelation of cobalt at the surface of the $\mathrm{Co}_{3} \mathrm{O}_{4} \mathrm{P}$ or destabilization of the particle surfaces are determining factors, and that molecules efficient for $\mathrm{Co}^{2+}$-binding in solution, may not be efficient for particles dissolution.

The $\mathrm{Co}_{3} \mathrm{O}_{4} \mathrm{P}$ are mixed-valence cobalt oxide particles, with $\mathrm{Co}(\mathrm{II})$ and $\mathrm{Co}(\mathrm{III})$. Therefore, destabilization of the particle surface by modifying the $\mathrm{Co}(\mathrm{II}) / \mathrm{Co}(\mathrm{III})$ equilibrium is probably an important step of $\mathrm{Co}_{3} \mathrm{O}_{4} \mathrm{P}$ dissolution, as it was described for mixed-valence iron oxides.

This prompted us to review the literature (Table 1), and to develop a strategy based on the hypotheses previously established for other metallic oxide particles dissolution. Particle dissolution depends mainly on three mechanisms: 1) protonation, in which protons are competing with the positively charged cations 
at the surface of the particle, 2) reduction, which leads to the destabilization of the particle surface by reducing the lattice metal cations thus modifying their preferred coordination and leading to the release of the dissolved cation and 3) chelation, acting directly at the particle surface or in solution. It is also of importance to note that a same molecule can act both as a chelator and as a redox agent, as it has been reported for ascorbate (Huang et al., 2017; Suter et al., 1991) and siderophores (Bi et al., 2010; Kraemer, 2004; Saad et al., 2017). For siderophores, literature data also propose a proton-promoted dissolution mechanisms (Kraemer, 2004).

We also combined molecules with different properties to reach a higher efficacy. Indeed, Joseph et al. demonstrated the positive effect of the combination of citric acid, EDTA and ascorbic acid for dissolving hematite at $\mathrm{pH} 2.8$ (Joseph et al. 1996). Ascorbic acid initiated the dissolution by Fe(III) reduction into $\mathrm{Fe}(\mathrm{II})$ at the particle surface. In addition ascorbate can reduce Fe(III)-EDTA complexes formed in solution, and the resulting $\mathrm{Fe}(\mathrm{II})$-EDTA complex is proposed to accelerate the reductive particle dissolution. Actually, the citric acid-EDTA-ascorbic acid was shown to completely dissolve hematite at pH 3 (Ananthan et al. 2003).

Whatever the tested molecule, the overall dissolution in ALF was always higher than in Gamble's. In contrast, the dissolution enhancement observed with given molecules as compared to untreated controls was higher in Gamble's than in ALF. As an example in the biphasic model, the dissolution increased 18.5 fold in the presence of ascorbate and DTPA as compared to controls in 7 days, and 2.1 fold only in ALF. The higher dissolution obtained in ALF suggests that the effect of $\mathrm{pH}$ is dominating over the effect of (reductive) complexation in the process of $\mathrm{Co}_{3} \mathrm{O}_{4} \mathrm{P}$ dissolution, at least at short incubation times. This is not true anymore at longer incubation times, as demonstrated by the significantly higher dissolution rate observed for $\mathrm{Co}_{3} \mathrm{O}_{4} \mathrm{P}$ dissolution at day 28 in presence of DFOB with or without ascorbate or oxalate, and with ascorbate and $50 \mathrm{mM}$ EDTA (Figure 5) as compared to the control. On the other hand, the very low level of $\mathrm{Co}_{3} \mathrm{O}_{4} \mathrm{P}$ dissolution in Gamble's might be explained by a competition for complexation between the $\mathrm{Ca}$ and $\mathrm{Mg}$ cations present at high concentration in the medium and $\mathrm{Co}$ towards the added chelating molecules. We tested this hypothesis by incubating $\mathrm{Co}_{3} \mathrm{O}_{4} \mathrm{P}$ in HEPES and EDTA in presence of $\mathrm{Ca}^{2+}$ and $\mathrm{Mg}^{2+}$ at concentrations found in Gamble's, and the 7-day dissolution was reduced 32 fold in the presence of these two cations (data not shown). The low but significant $\mathrm{Co}_{3} \mathrm{O}_{4} \mathrm{P}$ 
dissolution increase obtained with L-Cys and GSH in Gamble's (Figure 2) also supports this hypothesis, since these compounds are poor $\mathrm{Ca}^{2+}$ or $\mathrm{Mg}^{2+}$ ligands. We cannot exclude however, that these compounds contribute to $\mathrm{Co}_{3} \mathrm{O}_{4} \mathrm{P}$ dissolution by other mechanisms, such as a redox effect. In Gamble's medium, the dissolution process could also be inhibited by possible "passivation" agents such as proteins or small molecules as phosphate, which could irreversibly bind to the particles and protect their surface against degradation.

Overall, our results strongly suggest that the combination of two molecules with different mechanisms of action on cobalt oxide particles provides an effective strategy to increase their dissolution in the two lung fluid surrogates (Tables 2 and 3). Of particular interest is the important long-term effect observed in the dynamic assay in ALF, since these conditions correspond to the main retention compartment for $\mathrm{Co}_{3} \mathrm{O}_{4} \mathrm{P}$ in the lungs, following macrophage uptake. Ascorbate associated with chelating molecules as EDTA, DTPA or DFOB showed a higher efficacy than when used alone. This suggests that, in vivo, such combinations would be of great interest by promoting the particles dissolution using a redox mechanisms, coupled by the chelation of the dissolved $\mathrm{Co}^{2+}$ ions. Translocation from lungs to blood would consequently occur, accelerating lung clearance and decreasing the time of irradiation. The subsequent committed effective dose in case of inhalation of radioactive cobalt compounds would thus be limited. An important issue in the identification of new decorporating drugs, is their potential toxicity. Indeed, a crucial point in the development of a treatment for use in humans is its absence of toxicity. In this respect, it is important to note that among the molecules used in combination that allow the highest dissolution rate of $\mathrm{Co}_{3} \mathrm{O}_{4} \mathrm{P}, \mathrm{DTPA}$, EDTA, ascorbate and DFOB are FDA approved molecules. Although the unspecific chelation of other metallic ions cannot be excluded, no major side effects have been reported for these molecules. Ca-DTPA has been used in workers contaminated with actinides for few decades. As reported by the FDA administration and in a case study (Grappin et al. 2007), no evidence for side effects in $95 \%$ of the treated workers was reported, even after long term administration. 


\section{Conclusions}

634 In the present study, we evaluated the ability of various molecules to increase the dissolution of $\mathrm{Co}_{3} \mathrm{O}_{4} \mathrm{P}$

635 in lung fluid surrogates. Dissolution was assessed using two complementary acellular in vitro models, 636 representative of retention compartments following pulmonary contamination with poorly soluble cobalt 637 particles. We first demonstrated that DTPA, the currently recommended decorporating treatment, had 638 no significant effect on the dissolution of $\mathrm{Co}_{3} \mathrm{O}_{4} \mathrm{P}$. We then showed that combining redox active 639 molecules with chelating agents led to a better efficacy for $\mathrm{Co}_{3} \mathrm{O}_{4} \mathrm{P}$ dissolution than each molecule used 640 alone as already reported for the dissolution of mixed-valence iron oxide particles. From the present 641 work, a small set of combinations involving FDA- approved molecules, very promising for new 642 decorporation strategies, were identified and can be now tested on main cellular targets, such as 643 pulmonary macrophages. 


\section{References}

646 Afonso, M.D., Morando, P.J., Blesa, M.A., Banwart, S., Stumm, W., 1990. The Reductive Dissolution of 647 Iron-Oxides by Ascorbate - the Role of Carboxylate Anions in Accelerating Reductive Dissolution. 648 Journal of Colloid and Interface Science 138, 74-82.

649 ASN, 2008. Intervention médicale en cas d'événement nucléaire ou radiologique. 650 https://www.asn.fr/Professionnels/Les-Guides-de-I-ASN/Guide-national-d-intervention-medicale-enBarceloux, D.G., 1999. Cobalt. J Toxicol Clin Toxicol 37, 201-206.

Bi, Y., Hesterberg, D.L., Duckworth, O.W., 2010. Siderophore-promoted dissolution of cobalt from hydroxide minerals. Geochimica et Cosmochimica Acta 74, 2915-2925.

Bornhorst, J.A., Falke, J.J., 2000. Purification of proteins using polyhistidine affinity tags. Methods Enzymol 326, 245-254.

Cho, W.S., Duffin, R., Thielbeer, F., Bradley, M., Megson, I.L., MacNee, W., Poland, C.A., Tran, C.L., Donaldson, K., 2012. Zeta Potential and Solubility to Toxic lons as Mechanisms of Lung Inflammation Caused by Metal/Metal Oxide Nanoparticles. Toxicological Sciences 126, 469-477.

Collier, C.G., Pearce, M.J., Hodgson, A., Ball, A., 1992. Factors affecting the in vitro dissolution of cobalt oxide. Environ Health Perspect 97, 109-113.

Davis, K., Marsh, J.W., Gerondal, M., Bailey, M.R., Le Guen, B., 2007. Assessment of intakes and doses to workers followed for 15 years after accidental inhalation of 60CO. Health Phys 92, 332-344.

Delangle, P., Mintz, E., 2012. Chelation therapy in Wilson's disease: from D-Penicillamine to the design of selective bioinspired intracellular $\mathrm{Cu}(\mathrm{I})$ chelators. Dalton transactions 41, 6359-6370.

Dubbin, W.E., Bullough, F., 2017. Dissolution of Al-Substituted Goethite in the Presence of Ferrichrome and Enterobactin at pH 6.5. Aquatic Geochemistry 23, 61-74.

Fisher, D.R., Dunavant, B.G., 1978. Internal decontamination of radiocobalt. Health Phys 35, 279-285. Ghasemi, K., Rezvani, A.R., Shokrollahi, A., Moghimi, A., Gavahi, S., Garcia-Granda, S., MendozaMerono, R., 2014. A proton transfer and a cobalt(II) compound including 2,6-pyridinedicarboxylate and o-phenylenediamine ions: Synthesis, characterization, crystal structure and solution study. Comptes Rendus Chimie 17, 1221-1229.

Giampreti, A., Lonati, D., Ragghianti, B., Ronchi, A., Petrolini, V.M., Vecchio, S., Locatelli, C.A., 2016. NAcetyl-Cysteine as Effective and Safe Chelating Agent in Metal-on-Metal Hip-Implanted Patients: Two Cases. Case Rep Orthop 2016, 8682737.

Gremy, O., Tsapis, N., Chau, Q., Renault, D., Abram, M.C., Van der Meeren, A., 2010. Preferential decorporation of americium by pulmonary administration of DTPA dry powder after inhalation of aged $\mathrm{PuO}(2)$ containing americium in rats. Radiat Res 174, 637-644.

Griffiths, N., Van der Meeren, A., Angulo, J., Vincent-Naulleau, S., in press. Research on the Radiotoxiocology of plutonium: consideration of the 3Rs - Replace, Reduce, Refine. Health Physics Journal.

Griffiths, N.M., Coudert, S., Moureau, A., Laroche, P., Angulo, J.F., Van der Meeren, A., 2016. Forecasting the In Vivo Behavior of Radiocontaminants of Unknown Physicochemical Properties Using a Simple In Vitro Test. Health Phys 111, 93-99.

Guilmette, R.A., Muggenburg, B.A., 1993. Decorporation therapy for inhaled plutonium nitrate using repeatedly and continuously administered DTPA. Int J Radiat Biol 63, 395-403.

Hedberg, Y., Gustafsson, J., Karlsson, H.L., Moller, L., Wallinder, I.O., 2010. Bioaccessibility, bioavailability and toxicity of commercially relevant iron- and chromium-based particles: in vitro studies with an inhalation perspective. Particle and Fibre Toxicology 7.

Huang, X.P., Hou, X.J., Song, F.H., Zhao, J.C., Zhang, L.Z., 2017. Ascorbate Induced Facet Dependent Reductive Dissolution of Hematite Nanocrystals. Journal of Physical Chemistry C 121, 1113-1121. ICRP, 2016. Occupational Intakes of Radionuclides : Part 2., Annals of the ICRP Publication 134. . 
Joseph, S., Visalakshi, G., Venkateswaran, G., Moorthy, P.N., 1996. Dissolution of haematite in citric acid-EDTA-ascorbic acid mixtures. Journal of Nuclear Science and Technology 33, 479-485.

Jurisson, S.S., Benedict, J.J., Elder, R.C., Deutsch, E., 1983. Calcium affinity of coordinated diphosphonate ligands. Single-crystal structure of $[(\mathrm{en}) 2 \mathrm{Co}(\mathrm{O} 2 \mathrm{P}(\mathrm{OH}) \mathrm{CH} 2 \mathrm{P}(\mathrm{OH}) \mathrm{O} 2)] \mathrm{ClO} 4 . \mathrm{H} 2 \mathrm{O}$. Implications for the chemistry of technetium-99m-diphosphonate skeletal imaging agents. Inorganic Chemistry 22, 1332-1338.

Kastury, F., Smith, E., Juhasz, A.L., 2017. A critical review of approaches and limitations of inhalation bioavailability and bioaccessibility of metal(loid)s from ambient particulate matter or dust. Sci Total Environ 574, 1054-1074.

Kraemer, S.M., 2004. Iron oxide dissolution and solubility in the presence of siderophores. Aquatic Sciences 66, 3-18.

Kreyling, W.G., Andre, S., Collier, C.G., Ferron, G.A., Metivier, H., Schumann, G., 1991. Interspecies Comparison of Lung Clearance after Inhalation of Monodisperse, Solid Cobalt Oxide Aerosol-Particles. Journal of Aerosol Science 22, 509-535.

Kreyling, W.G., Cox, C., Ferron, G.A., Oberdorster, G., 1993. Lung clearance in Long-Evans rats after inhalation of porous, monodisperse cobalt oxide particles. Exp Lung Res 19, 445-467.

Lakind, J.S., Stone, A.T., 1989. Reductive Dissolution of Goethite by Phenolic Reductants. Geochimica Et Cosmochimica Acta 53, 961-971.

Le Guen, B., Ansoborlo, E., 2005. Le cobalt et ses isotopes [in French]. Toxicologie-Pathologie professionnelle, 1-11.

Levitskaia, T.G., Creim, J.A., Curry, T.L., Luders, T., Morris, J.E., Woodstock, A.D., Levinson, B., Thrall, K.D., 2010a. Evaluation of Cuprimine and Syprine for decorporation of (60)Co and (210)Po. Health Phys 98, 471-479.

Levitskaia, T.G., Creim, J.A., Curry, T.L., Luders, T., Peterson, J.M., Thrall, K.D., Levinson, B., 2011. Evaluation of Cuprimine(R) and Syprine(R) for decorporation of radioisotopes of cesium, cobalt, iridium and strontium. Health Phys 101, 118-127.

Levitskaia, T.G., Morris, J.E., Creim, J.A., Woodstock, A.D., Luders, T., Curry, T.L., Thrall, K.D., 2010b. Aminothiol receptors for decorporation of intravenously administered $(60)$ Co in the rat. Health Phys 98, 53-60.

Llobet, J.M., Domingo, J.L., Corbella, J., 1986. Comparison of the effectiveness of several chelators after single administration on the toxicity, excretion and distribution of cobalt. Arch Toxicol 58, 278-281.

Llobet, J.M., Domingo, J.L., Corbella, J., 1988. Comparative effects of repeated parenteral administration of several chelators on the distribution and excretion of cobalt. Res Commun Chem Pathol Pharmacol 60, 225-233.

Lundborg, M., Falk, R., Johansson, A., Kreyling, W., Camner, P., 1992. Phagolysosomal pH and dissolution of cobalt oxide particles by alveolar macrophages. Environ Health Perspect 97, 153-157.

Marques, M.R.C., Loebenberg, R., Almukainzi, M., 2011. Simulated Biological Fluids with Possible Application in Dissolution Testing. Dissolution Technologies 18, 15-28.

Matsumoto, M., Suzuki, M., Kano, H., Aiso, S., Yamazaki, K., Fukushima, S., 2012. Carcinogenicity of ortho-phenylenediamine dihydrochloride in rats and mice by two-year drinking water treatment. Archives of Toxicology 86, 791-804.

Ortega, R., Bresson, C., Darolles, C., Gautier, C., Roudeau, S., Perrin, L., Janin, M., Floriani, M., Aloin, V., Carmona, A., Malard, V., 2014. Low-solubility particles and a Trojan-horse type mechanism of toxicity: the case of cobalt oxide on human lung cells. Particle and Fibre Toxicology 11, 14.

Panias, D., Taxiarchou, M., Paspaliaris, I., Kontopoulos, A., 1996. Mechanisms of dissolution of iron oxides in aqueous oxalic acid solutions. Hydrometallurgy 42, 257-265.

Pazzaglia, U.E., Apostoli, P., Congiu, T., Catalani, S., Marchese, M., Zarattini, G., 2011. Cobalt, chromium and molybdenum ions kinetics in the human body: data gained from a total hip replacement with massive third body wear of the head and neuropathy by cobalt intoxication. Arch Orthop Trauma Surg $131,1299-1308$. 
Pelfrene, A., Cave, M.R., Wragg, J., Douay, F., 2017. In Vitro Investigations of Human Bioaccessibility from Reference Materials Using Simulated Lung Fluids. International Journal of Environmental Research and Public Health 14.

Pujol, A.M., Gateau, C., Lebrun, C., Delangle, P., 2009. A Cysteine-Based Tripodal Chelator with a High Affinity and Selectivity for Copper(I). Journal of the American Chemical Society 131, 6928-6929.

Pujol, A.M., Gateau, C., Lebrun, C., Delangle, P., 2011. A series of tripodal cysteine derivatives as watersoluble chelators highly selective for Copper (I). Chemistry- A European Journal 17, 4418-4428. REMM, Radiation Countermeasures for Treatment of Internal Radiation Contamination. .

Rump, A., Becker, B., Eder, S., Lamkowski, A., Abend, M., Port, M., 2018. Medical management of victims contaminated with radionuclides after a "dirty bomb" attack. Military Medical Research 5, 27. Russell, W., Burch, R., 1959. Ch.4. The sources, incidences and removal of inhumanity., In: London, K.M. (Ed.), The principle of humane experimental technique. .

Saad, E.M., Sun, J.Y., Chen, S.O., Borkiewicz, O.J., Zhu, M.Q., Duckworth, O.W., Tang, Y.Z., 2017. Siderophore and Organic Acid Promoted Dissolution and Transformation of $\mathrm{Cr}$ (III)- $\mathrm{Fe}$ (III)(oxy)hydroxides. Environmental Science \& Technology 51, 3223-3232.

Staack, G., Cheng, Y.-S., Zhou, Y., LaBone, T., 2017. Determination of In Vitro Lung Solubility and Intaketo-Dose Conversion Factors for Tritiated LaNi4.15AI0.85 and 13X Zeolite. Fusion Science and Technology 71, 570-574.

Stefaniak, A.B., 2010. Persistence of tungsten oxide particle/fiber mixtures in artificial human lung fluids. Particle and Fibre Toxicology 7.

Stone, A.T., Morgan, J.J., 1984. Reduction and Dissolution of Manganese(lii) and Manganese(Iv) Oxides by Organics .2. Survey of the Reactivity of Organics. Environmental Science \& Technology 18, 617-624. Suter, D., Banwart, S., Stumm, W., 1991. Dissolution of Hydrous Iron(lii) Oxides by Reductive Mechanisms. Langmuir 7, 809-813.

Uboldi, C., Orsiere, T., Darolles, C., Aloin, V., Tassistro, V., George, I., Malard, V., 2016. Poorly soluble cobalt oxide particles trigger genotoxicity via multiple pathways. Particle and Fibre Toxicology 13, 5. Van der Meeren, A., Angulo, J.F., Bohand, S., Griffiths, N.M., 2019. A quick and simple in vitro assay to predict bioavailability of actinides following accidental exposure. Toxicology in Vitro 58, 142-149.

Weber, W., Doyle-Eisele, M., Seilkop, S.K., Guilmette, R., 2012. Biokinetics of Systemically Distributed 60 Co in the Rat: An Experimental Model Useful in Evaluating Medical Countermeasures for Internal Contamination. Health Phys 103, 474-483.

Yang, L.Q., Crans, D.C., Miller, S.M., la Cour, A., Anderson, O.P., Kaszynski, P.M., Godzala, M.E., Austin, L.D., Willsky, G.R., 2002. Cobalt(II) and cobalt(III) dipicolinate complexes: Solid state, solution, and in vivo insulin-like properties. Inorganic Chemistry 41, 4859-4871.

Zhao, J., Liu, Y., Pan, B., Gao, G.Q., Liu, Y., Liu, S.Q., Liang, N., Zhou, D.D., Vijver, M.G., Peijnenburg, W.J.G.M., 2017. Tannic acid promotes ion release of copper oxide nanoparticles: Impacts from solution $\mathrm{pH}$ change and complexation reactions. Water Research 127, 59-67.

Zinder, B., Furrer, G., Stumm, W., 1986. The Coordination Chemistry of Weathering .2. Dissolution of Fe(lii) Oxides. Geochimica Et Cosmochimica Acta 50, 1861-1869.

Zylicz, E., Zablotna, R., Geisler, J., Szot, Z., 1975. Effects of DTPA on the deposition of 65Zn, 60Co and 144Ce in pregnant rat and in foetoplacental unit. Int J Radiat Biol Relat Stud Phys Chem Med 28, 125136. 